\title{
A categoria dos Auditores Fiscais da Receita Federal do Brasil: a (des) construção da identidade profissional
}

\section{Secretariat of the Federal Revenue of Brazil officers: considerations about professional identity construction}

\author{
Mônica de Fátima Bianco ${ }^{1}$ \\ Antonia de Lourdes Colbari ${ }^{2}$ \\ Augusto Oliveira da Silva Neto ${ }^{3}$
}

\begin{abstract}
Resumo
Este artigo busca revelar o processo de desenvolvimento da categoria dos auditores fiscais da Receita Federal do Brasil (AFRFBs), a partir das mudanças no contexto social e profissional, e a forma como essas mutações concorreram para a construção de uma identidade profissional própria desses servidores. O que se pretende é entender como o contexto político-econômico vem alterando as percepções que esses profissionais têm de si próprios e como as reformas transformaram o modo de exercerem suas funções. A pesquisa, que se dá a partir de uma proposta de transação "quantiquali”, permitiu explorar, na trilha teórica de Dubar, aspectos relevantes do contínuo processo de construção das identidades profissionais ou de perfis identitários desses servidores. Os conhecimentos sobre o trabalho e as formas de identificação profissional na categoria dos auditores fiscais da Receita Federal do Brasil podem contribuir para a reflexão sobre relações de trabalho e processos de gestão pública no Brasil.
\end{abstract}

Palavras-chave: auditores fiscais; Receita Federal; identidade profissional.

\begin{abstract}
The article aims to reveal the process of career development of tax auditors of the Brazilian Inland Revenue (auditores fiscais da Receita Federal do Brasil), from changes in the social and professional context and how these changes have contributed to the construction of a professional identity of these servers. The aim is to understand how the politicaleconomic context is changing the perceptions that these professionals have of themselves and how the reforms transformed the way in which the tax auditors carry out their functions. The research resulting from a quantitative-qualitative transaction proposal made it possible to explore, in accordance with the theory of Claude Dubar, relevant aspects in the continuous process of construction of professional identities. Knowledge of the work and forms of identification of tax auditors at the Brazilian Inland Revenue may contribute to reflections on work relationships and processes of public management in Brazil.
\end{abstract}

Key words: auditores fiscais; Receita Federal; professional identity.

\section{Introdução}

As transformações sociais e econômicas ocorridas no final do século passado, e ainda em curso neste início de século, produziram alterações nas formas de gestão organizacional, tornando-as mais ágeis, para que acompanhem a crescente demanda por produtos e serviços realizada por consumidores cada vez mais exigentes.

\footnotetext{
Artigo submetido em agosto e aceito para publicação em outubro de 2009.

${ }^{1}$ Doutora em Engenharia de Produção - Poli/USP. Professora e Pesquisadora do Departamento de Administração e do PPGAdm - UFES. Avenida Fernando Ferrari, 514 - Campus Universitário Alaor de Queiroz Araújo - Vitória/ES, CEP: 29075-910. E-mail: mfbianco@ig.com.br .

${ }^{2}$ Doutora em Sociologia - Instituto Universitário de Pesquisas do Rio de Janeiro (IUPERJ). Professora da Universidade Federal do Espírito Santo (UFES)

e Pesquisadora do CNPq. Avenida Fernando Ferrari, 514 - Campus Universitário Alaor de Queiroz Araújo - Vitória/ES, CEP: 29075-910. E-

mail: alcolbari@terra.com.br.

${ }^{3}$ Mestre em Administração - Universidade Federal do Espírito Santo (UFES). Auditor Fiscal da Receita Federal do Brasil. Rua Pietrângelo di Biasi, 176, Centro, Vitória/ES. CEP: 29010-480. E-mail:aosneto@hotmail.com .
} 
Ainda que de forma tímida e pontualmente localizada em alguns órgãos de maior capacidade de organização, o setor público tende a acompanhar essas mudanças nos padrões de gestão. Até agora, as alterações foram mais profundas no aspecto tecnológico, com o uso abrangente da tecnologia da informação e da internet para atendimento dos cidadãos e a simplificação de procedimentos.

Apesar da forte resistência por parte dos servidores, as mudanças pretendidas no setor público vêm sendo paulatinamente realizadas. O modelo gerencialista de administração pública proposto por Bresser Pereira (1996), mesmo não implantado de forma ostensiva, vem ganhando terreno nas organizações públicas, com várias de suas propostas estando em curso hoje no serviço público.

A Secretaria da Receita Federal do Brasil (RFB) vem implantando várias mudanças na sua forma de gestão, além de adotar conceitos que atendem especificamente às propostas da nova administração pública de BresserPereira. É o caso do emprego da expressão "cliente" no lugar de "contribuinte" e da transformação de chefes em "gestores". Essa guinada se choca com a ordem burocrática arraigada no serviço público brasileiro, em geral, e consequentemente altera o perfil identitário de seus servidores.

É impossível delimitar se os auditores fiscais da Receita Federal constituem apenas um corpo técnico do serviço público ou se apresentam características de uma categoria com saberes e formas de exercício profissional específicos de um determinado ofício. Mesmo assim, este artigo busca revelar de que forma esses servidores enfrentam o processo de enfraquecimento de sua atividade. Tal processo tem gerado uma verdadeira crise na formação de sua identidade profissional - nos moldes da conceituação estabelecida por Dubar (2003, 2005, 2006) -, levando a novas formas de ver a instituição e também de se identificar com (e se reconhecer na) tarefa desempenhada.

O propósito do artigo é buscar as consequências dessa mutação nos perfis identitários dos integrantes da categoria dos auditores fiscais, com base numa pesquisa realizada no estado do Espírito Santo. O percurso seguido inclui a abordagem do desenvolvimento da carreira (do surgimento aos dias atuais), o destaque do papel da burocracia nos serviços públicos brasileiros e a análise dos impactos das mudanças propostas pelo modelo gerencialista na forma como esses servidores se veem no papel de agentes públicos, bem como as consequências desse processo para a organização Receita Federal.

\section{Aspectos históricos da carreira dos auditores fiscais}

O pagamento de prestações monetárias aos governantes na forma de tributos pode ter como propósito custear a manutenção da coisa pública - promovendo maior distribuição das riquezas e melhorias para a população como pode, simplesmente, tratar-se de uma intervenção no domínio econômico visando salvaguardar os interesses de determinada classe social. De uma forma ou de outra, é fato presente na história dos países e determinante para o equilíbrio financeiro do Estado.

Hodiernamente, nos países ocidentais, essa arrecadação está entregue a funcionários do Estado que têm o dever de zelar pela "coisa pública", garantindo a independência, a rigidez e a isenção na coleta e no repasse desses valores aos cofres públicos.

Uma das mais antigas profissões da humanidade, o cobrador de tributos integra uma daquelas categorias profissionais cuja atividade é inerente ao próprio Estado. Desempenhando uma função em relação a qual não pode existir paralelo na esfera privada, sua importância para o funcionamento da máquina estatal é estabelecida pela delegação de poder que deve coibir o descumprimento da lei tributária pelos agentes econômicos.

A Secretaria da Receita Federal do Brasil (RFB), apesar do pouco tempo de existência, é o órgão estatal responsável pela normatização, fiscalização e arrecadação dos tributos federais. Nela trabalham os auditores fiscais da Receita Federal do Brasil (AFRFBs), agentes do Estado e autoridades legalmente constituídas para o exercício da atividade fiscal em âmbito federal. 
A ex-Secretaria da Receita Federal, hoje RFB, foi criada em 1964, a partir da reunião de diversos outros órgãos estatais que exerciam atividades correlatas e, desde aquela época, tem sido a única organização com essa atribuição no país. Entretanto, a organização, na avaliação de seus integrantes, nasceu em crise, devido às muitas conformações adotadas ao longo de sua existência. Em um primeiro momento, um conjunto de órgãos isolados foi agregado numa única instituição, com suas culturas e quadros profissionais diversos. Recentemente, ocorreu a fusão com a Secretaria da Receita Previdenciária, e tal fato acabou desencadeando mais um ciclo de crise entre seus funcionários.

Os fiscais da Receita Federal já foram conhecidos como fiscais de tributos federais, técnicos de tributação, controladores de arrecadação federal, agentes aduaneiros, guardas aduaneiros e auditores fiscais do Tesouro Nacional. Após a criação da RFB, tornaram-se conhecidos como auditores fiscais da Receita Federal do Brasil, e há proposta de virem a se chamar auditores fiscais da República.

As atividades profissionais dos AFRFBs também passaram por uma mutação, principalmente, a partir da última década do século XX, processo que se acelerou neste início de século XXI. Nesse sentido, deve ser observado que o gerencialismo proposto por Bresser-Pereira (1996) já embutia a proposta de transformar o contribuinte em cidadão e o agente fiscal não mais em autoridade, mas em servidor posto a serviço desse cliente.

Mesmo que a capacidade intelectual seja ainda o necessário diferencial que move toda a carreira, as formas de exercício profissional paulatinamente foram transformadas. Os auditores, antes detentores de controle sobre sua atividade (elegiam os alvos de pesquisa e seleção de contribuintes para fiscalização e eram portadores das informações necessárias à execução das tarefas), passaram a desempenhar um trabalho reativo, de cruzamento de informações vindas de grupos especializados.

Além disso, deixaram de ser a autoridade responsável pela fiscalização e pelo desembaraço aduaneiro para se tornarem agentes delegados das autoridades administrativas que, de fato, exercem essa autoridade. A busca desse novo perfil profissional, mais adequado a um analista de informações e menos a um investigador que, por natureza, age proativamente, vem conferindo aos auditores aquilo que Dubar (2006) denomina crise de identidade.

No Espírito Santo, as duas unidades da Receita Federal em Vitória, a Delegacia da Receita Federal e a Alfândega, respondem por toda a fiscalização, arrecadação e atendimento aos contribuintes do estado. Os auditores dessas duas unidades administrativas compuseram o universo de pesquisa, dado a necessária delimitação do objeto. Essa composição, resumida nos quadros apresentados a seguir, pode revelar as características de seus integrantes: predominância do sexo masculino, dos quem tem mais de 10 anos de profissão e daqueles com formação superior em administração, direito e engenharia.

\section{Tabela 1 - Distribuição dos AFRFBs lotados em Vitória (ES) por faixa etária}

\begin{tabular}{lccccc} 
& \multicolumn{2}{c}{ Homens } & \multicolumn{2}{c}{ Mulheres } & Total \\
Idades (anos) & ALF & DRF/DRP & ALF & DRF/DRP & \\
\hline$<30$ & 2 & 1 & 1 & 3 & 7 \\
\hline $31-40$ & 17 & 21 & 3 & 5 & 46 \\
$41-50$ & 37 & 50 & 9 & 40 & 136 \\
\hline $51-60$ & 13 & 32 & 3 & 21 & 69 \\
$>61$ & 6 & 3 & 0 & 1 & 10 \\
$\sum$ & 75 & 107 & 16 & 70 & 268 \\
\hline \hline
\end{tabular}

Fonte: Setor de gestão de pessoas - SEGEP/DRF/Vit. 
Tabela 2 - Tempo de atividade na carreira

\begin{tabular}{|cccc}
\hline \multicolumn{4}{c}{ Tempo de serviço (anos) } \\
\hline$<2$ & ALF & DRF/DRP & TOTAL \\
\hline $2-9$ & 7 & 6 & 13 \\
\hline $10-17$ & 33 & 47 & 80 \\
\hline $18-25$ & 11 & 79 & 115 \\
\hline 26 & 4 & 7 & 49 \\
\hline$\sum$ & 91 & 177 & 11 \\
\hline
\end{tabular}

Fonte: Setor de gestão de pessoas - SEGEP/DRF/Vit.

Tabela 3 - Formação acadêmica dos AFRFBs de Vitória (ES)

\begin{tabular}{|c|c|c|c|}
\hline \multicolumn{4}{|c|}{ Formação } \\
\hline & ALF & DRF/DRP & TOTAL \\
\hline Engenharia & 29 & 91 & 120 \\
\hline Direito & 23 & 35 & 58 \\
\hline Administração & 13 & 36 & 49 \\
\hline Contábeis & 14 & 11 & 25 \\
\hline Economia & 11 & 13 & 24 \\
\hline Ciência da computação & 3 & 4 & 7 \\
\hline Letras & 3 & 2 & 5 \\
\hline Estatística & 2 & 1 & 3 \\
\hline Serviço social & 2 & 1 & 3 \\
\hline Matemática & 1 & 1 & 2 \\
\hline Arquitetura & 1 & 1 & 2 \\
\hline Física & 1 & 0 & 1 \\
\hline Medicina & 0 & 1 & 1 \\
\hline Odontologia & 0 & 1 & 1 \\
\hline$\sum$ & 103 & 198 & 301 \\
\hline
\end{tabular}

Fonte: Setor de gestão de pessoas - SEGEP/DRF/Vit.

Essas são as principais informações acerca desses profissionais que exercem suas atividades na RFB. Neste artigo, eles terão suas relações com a organização e com seus pares investigadas, tendo em vista a busca de indícios que possibilitem delinear seus perfis identitários profissionais, que são perpassados pela discussão sobre a transição entre a burocracia e o gerencialismo, conforme será visto a seguir.

\section{Da burocracia ao gerencialismo}

A sociologia de Max Weber $(2002,2004)$ - sobretudo, no que diz respeito à ação social, às formas de dominação e à burocracia moderna - compõe um arcabouço imprescindível para a análise de uma organização essencialmente burocrática, onde as relações existentes entre os indivíduos são fortemente referenciadas pela racionalidade legal. 
Os conceitos weberianos de ação e de relação social, fundamentados nas motivações e na intersubjetividade dos atores, são fundamentais para compreendermos a formação dos agrupamentos sociais e, consequentemente, o desenvolvimento dos processos identitários. No caso dos grupos profissionais, a sua constituição envolve relações entre indivíduos que compartilham um tipo de inserção no mundo do trabalho; portanto, um perfil profissional delineado por saberes e experiências comuns.

O entendimento da formação da categoria profissional AFRFB, remete também ao conceito de dominação de Weber (2004), que é "a probabilidade de encontrar obediência para ordens específicas (ou todas) dentro de determinado grupo de pessoas", mas que não representa necessariamente toda forma de exercício de poder ou de influência. A dominação é também chamada autoridade e pode estar fundada em razões diversas.

Para que a dominação de um conjunto de pessoas possa operar de forma satisfatória, é necessário que haja um quadro administrativo que execute as ações necessárias de forma estável. Essas relações podem adquirir diversas formas, mas, de um modo geral, a dominação requer a crença em um tipo de legitimidade para que possa se estabilizar e garantir o exercício da dominação.

As formas de dominação legítima podem ser de três tipos: a de caráter racional, a de caráter tradicional e a de caráter carismático. Como não é objetivo deste artigo aprofundar o estudo sobre todas as formas de dominação, o foco será lançado sobre aquela que serve de justificativa teórica para a burocracia proposta por Weber (2002, 2004) - a dominação racional. Ela repousa sua forma de legitimação no ordenamento jurídico, pois a impessoalidade dos atos, a investidura nos cargos e a obediência resultam da crença na eficiência e no pacto social decorrente das leis.

Esta não é a visão de Crozier (1981). Apoiado em conceitos da escola interacionista, esse autor assevera serem as atividades humanas dependentes do sentimento humano de pertencimento a um grupo e da capacidade de integração com que as pessoas se entregam a elas, uma vez que apenas a perícia, a impessoalidade e a hierarquia são insuficientes para determinar a eficácia de suas atividades.

As mudanças no modelo burocrático são lentas, por conta da rigidez de suas estruturas. Para que qualquer mudança ocorra, é necessário reformular completamente a organização, pois "um sistema [...] cuja característica principal é a rigidez, não pode, naturalmente, adaptar-se facilmente à mudança e propenderá a resistir a qualquer modificação" (CROZIER, 1981).

Deslocando-se do nível conceitual para o histórico, observa-se que mudanças econômicas ocorridas a partir da década de 1970 ajudaram a restabelecer alguns dos pontos do ideário liberal, potencializado pela dinâmica dos países centrais que facilitou a mudança dos paradigmas vigentes.

O modelo burocrático da administração pública passou, desse modo, a ser questionado pelas novas formas de administração, que visam conferir maior eficiência ao Estado, com a aplicação de conceitos vindos das organizações privadas.

A administração pública passou a absorver essas ideais e várias mudanças oriundas do setor privado alimentaram a retórica pela reformulação das organizações burocráticas do Estado. Neste, passou a ser cobrada de seus membros maior eficiência no atendimento aos interesses da população, seja na prestação de serviços de qualidade, seja na redução do tamanho da máquina pública, objetivando, assim, conter os gastos públicos e conquistar a satisfação da sociedade.

Segundo Paula (2007), há uma tendência de que o Estado passe ter as organizações empresariais como referência para a construção de sua lógica administrativa, o que de alguma maneira explica a adoção das reformas no modelo estatal e a busca pelo gerencialismo como forma de alcançar excelência no serviço público. Se a burocracia pôde ser vista como a organização ideal, em função de ser uma forma de dominação baseada na lei, os formalismos passaram a ser vistos como expressão de exagero e um entrave ao desenvolvimento. 
Por sua vez, ao procurar remover esses entraves que dificultam a implantação de políticas públicas mais ágeis e, por conseguinte, com melhores resultados para os administrados - o modelo gerencial incorre na armadilha de aumentar o poder discricionário da autoridade administrativa e de possibilitar a concentração de poder nos gerentes públicos, medida que pode ser incompatível com o interesse público.

Grande parte das considerações teóricas deste artigo inspira-se tanto na abordagem de Weber (2002, 2004) sobre a burocracia e suas características elementares, quanto na compreensão da emergência do modelo gerencial para as relações profissionais existentes no serviço público, evidenciada nas propostas de Bresser Pereira (1996), que foi o precursor do mais recente movimento de modernização da gestão administrativa no país. Não cabe, aqui, a discussão a respeito das diversas teses sobre a reforma do Estado, razão pela qual a abordagem do tema fica restrita ao discurso normativo que embasa as tentativas de reestruturação do serviço público brasileiro nos últimos anos.

Bresser Pereira (1996) enfatiza a necessidade da mudança do modelo burocrático para o gerencial quando diz que "a administração pública burocrática clássica foi adotada porque era uma alternativa muito superior à administração patrimonialista do Estado". Ainda segundo Bresser Pereira (1996), a mudança do modelo patrimonialista para o burocrático não foi capaz de assegurar a eficiência que se pretendia, elevando gastos e comprometendo a qualidade dos serviços públicos.

A lógica burocrática é fortemente arraigada nas instituições públicas brasileiras, sendo sempre lembrada como sinônimo de ineficiência e de desperdício. Em uma tentativa de mudança desse contexto, Bresser Pereira iniciou em meados da década de 1990, quando de sua passagem pelo Ministério do Planejamento, um movimento que visava transformar o modelo burocrático do serviço público em um modelo gerencial.

O serviço público brasileiro não passou incólume às alterações ocorridas no âmbito mundial. Nesse sentido, vem experimentando novas formas de execução de suas tarefas, numa busca por mudanças na concepção da cultura existente, construindo-se uma nova dinâmica nas relações profissionais intersubjetivas e sendo proposta uma ressignificação das carreiras profissionais que o compõem. Isso vem se dando, principalmente, por meio de inovações que visam mudar a sua lógica burocrática.

Essas propostas de mudanças enfrentaram resistências internas, pois, historicamente, a administração pública brasileira tem se debatido entre duas forças antagônicas. Segundo Castor e José (1998), foram colocadas em lados opostos uma burocracia presa a formalidades e rituais, propensa à centralização e à ineficiência, além de refratária às tentativas de modernização do aparelho de Estado, e de outro, "correntes modernizantes da burocracia e seus próprios aliados políticos e empresariais".

Se as rotinas rígidas e o apego à hierarquia possibilitam um melhor controle das atividades organizacionais, sua existência tende a deslocar a referência do trabalho para o próprio processo, conforme entendimento de Crozier (1981), tornando a burocracia autorreferida e afastada dos objetivos organizacionais que lhe deram causa. Mais importantes que os fins a serem atingidos, passam a ser os meios de sua consecução.

Para Bresser Pereira (1996), essa é justamente uma das causas por que o modelo burocrático deve ser substituído pelo modelo gerencial na administração pública brasileira, pois "na verdade, a administração burocrática é lenta, cara, autorreferida, pouco ou nada orientada para o atendimento das demandas dos cidadãos". Essas propostas de transição, e as tentativas de sua implementação, têm reflexos sobre a identidade profissional dos servidores, a seguir analisadas.

\section{As identidades sociais e profissionais}

O estudo da identidade pressupõe um emaranhado de caminhos que podem ser adotados e se depara com um sério problema conceitual, dado que o termo encerra várias definições e abordagens. Os pesquisadores da psicologia social e os da sociologia têm estudado a identidade e suas formas de construção, manutenção, desconstrução e adaptação a fim de elucidar os processos pelos quais o indivíduo constrói sua identidade e como a conserva ou transforma. 
Certo é que o estudo da identidade, visto de uma perspectiva multidisciplinar, possibilita um maior entendimento do indivíduo, de seu processo de formação e das suas construções psicológicas e sociais. Além disso, facilita o acesso às informações que ajudarão a elaborar teorias dentro das ciências sociais, permitindo compreender melhor as formas de gestão das organizações, numa perspectiva que privilegie a subjetividade, colocando o ator social no centro de referência.

Para Dubar (2006), as formas identitárias podem ser derivadas de duas linhas de pensamento diversas. Podem ser encaradas como uma forma meramente contingente e baseada nos discursos ou estar ligadas a processos históricos de longa duração. Baseado nessa segunda corrente, Dubar (2006) afirma que a emergência de novas formas de individualidade é resultante aleatória de "processos que modificam os modos de identificação dos indivíduos em consequência das transformações mais significativas na organização econômica, política e simbólica das relações sociais", sem predominância de qualquer um deles no resultado final.

As recentes crises de identidade, conforme percebidas por Dubar (1998), derivam de contextos sociais e profissionais em constante mutação, decorrentes das diversas transformações que o mundo vem sofrendo de maneira acelerada nos últimos anos, as quais ainda não configuraram um modelo definido que indique uma tendência.

No entendimento de Pedro (2006), estudar a identidade:

Implica resgatar as atividades e a consciência do sujeito, o movimento e a dialética da definição de si mesmo; investigar identidade -"Quem sou eu?", "Quem somos nós?" - implica enveredar pela pluralidade das cosmovisões de sujeitos, o pensar, o sentir, o agir humano (individual e coletivo), as ideologias, a fim de captar as representações e significações do seu "estar no mundo".

Para Strauss (1999):

O conceito de identidade é tão esquivo quanto o é o senso que toda pessoa tem de sua própria identidade pessoal. Mas, seja o que for, a identidade está associada às avaliações decisivas feitas de nós mesmos - por nós mesmos ou pelos outros. Toda pessoa se apresenta aos outros e a si mesma, e se vê nos espelhos dos julgamentos que eles fazem dela.

Para Dubar (2005):

Não existe nenhuma identidade "essencial" em qualquer que seja o campo social e, a fortiori, na história humana. Todas as identidades são denominações relativas a uma época histórica e a um tipo de contexto social. Assim, todas as identidades são construções sociais e de linguagem que são acompanhadas, em maior ou menor grau, por racionalizações e reinterpretações que às vezes as fazem passar por essências intemporais.

Essa abordagem que Dubar (2005) chama de "abordagem sociológica das identidades" pretende articular duas dimensões do termo identidade. A primeira diz respeito à socialização biográfica, reportando à identidade reivindicada pelo próprio indivíduo e submetida ao reconhecimento alheio. A segunda refere-se à socialização relacional e está ligada a um contexto de ação social.

Para Machado (2003), "embora exista em cada indivíduo um senso de individualidade, a construção do autoconceito é inseparável do outro". A identidade é construída tendo como referencial as experiências de socialização, criando as formas ideais dentro de cada indivíduo que, por sua vez, irão moldar seus processos de absorção e de constituição identitária, permitindo a subjetivação de sua participação no contexto social.

A identidade social é, segundo Machado (2003), "o fruto da interação de mecanismos psicológicos e dos fatores sociais", constituindo o processo de identificação do indivíduo a partir da dinâmica social e das relações que se travam dentro dos grupos, possibilitando que o indivíduo crie mecanismos de seleção dos grupos com os quais mais se identifica e dos que ele não deseja pertencer. 
Esses elementos, que permitem ao sujeito buscar os grupos de referência para a constituição de sua identidade social, são os mesmos que levarão à rejeição de pessoas ou grupos considerados estranhos ou negativos à identificação em questão. É, pois, a identidade social o fruto da articulação mental de categorização, escolha e vinculação de um elemento a um grupo a partir de suas observações e análises psicológicas.

A formação da identidade no trabalho é um desdobramento da identidade social - ou mesmo uma espécie desta, dado que sua construção se dá pelo pertencimento a uma determinada categoria e pelo exercício de um papel profissional -, na qual o indivíduo reforça seu sentimento de inclusão no mundo do trabalho. A identificação com a organização denota um sentimento de proteção que o indivíduo possui ao se sentir pertencente a um determinado grupo que lhe confira status social ou profissional e que lhe possibilite sentir-se seguro tanto para desenvolver suas relações dentro da própria entidade, quanto no meio social onde estiver inserido.

A estrutura da organização molda o indivíduo em seu processo de construção subjetiva da identidade, conferindo-lhe certas informações que irão agir na sua forma de conviver com os pares no trabalho. Para Machado (2003):

O fato de viver sob uma estrutura institui uma espécie de mentalidade coletiva, com a qual o indivíduo se conforma, assimilando suas regras e normas de comportamento e estabelecendo vínculos afetivos com as pessoas com quem convive nesse ambiente.

Uma identificação negativa com a organização pode levar ao afastamento do sujeito, tanto por iniciativa própria, quanto por rejeição do grupo ou de um superior. No caso das organizações do serviço público, onde há estabilidade e dificilmente há exclusões, a falta de identificação com a organização pode descambar para problemas de ordem psicológica ou derivar para o assédio moral como forma de punição. Logo, segundo Machado (2005), a identidade é a imagem cognitiva que os integrantes de uma organização assimilam por intermédio de processos próprios.

\section{Método}

Um dos procedimentos utilizados para produzir o corpus da pesquisa foi a observação participativa "involuntária", considerando que um dos autores é integrante do universo da pesquisa. A posição do "nativo" foi fundamental não só para o delineamento do problema de pesquisa, mas também para a identificação de comportamentos e da forma de agir e pensar do grupo em estudo - como já dito anteriormente, limitado aos AFRFBs lotados no Espírito Santo - mormente, no que diz respeito ao seu processo de formação da identidade profissional.

Essa forma de observação participante, embora tida de maneira involuntária - dado que este não era o objetivo principal da inserção na categoria em estudo -, propiciou a elaboração de algumas proposições que foram se avolumando com o tempo e, naturalmente, passaram a fazer parte dos procedimentos metodológicos utilizados na execução desta pesquisa. Muito daquilo que se diz neste artigo está impregnado dessa vivência e conhecimento, sem que fique comprometido o rigor metodológico necessário à elaboração de um trabalho científico.

A metodologia empregada valeu-se de uma integração entre as características qualitativa e quantitativa de pesquisa, com três etapas distintas, a fim de suprir as lacunas existentes e já mencionadas (como a falta de estranhamento), visando aumentar o rigor com que os resultados foram tratados. Essa transação "quanti-quali" permitiu passar de uma etapa a outra da pesquisa com dados e referências mais sólidas.

Nas etapas em que a dimensão qualitativa foi preponderante, recorreu-se à análise de conteúdo - primeiro de tudo, num teste de associação de palavras; posteriormente, com o uso de análise temática - como forma apropriada de combater pressupostos e fugir das tentativas simplistas de compreensão das significações dos atores sociais investigados a partir das percepções dos pesquisadores. 
Esta atitude de vigilância crítica exige o "rodeio metodológico" e o emprego de "técnicas de ruptura" e afigura-se tanto mais útil para o especialista das ciências humanas, quanto mais ele tenha sempre uma impressão de familiaridade face ao seu objeto de análise. (BARDIN, 2006)

Na primeira pergunta formulada aos entrevistados, foi-lhes solicitado que associassem livremente palavras ao termo "Auditor Fiscal da Receita Federal". Foram ouvidos 20 auditores, aleatoriamente, não tendo sido estipulado um número limite de respostas. Ficou a critério do respondente dizer uma ou mais palavras de que se lembrasse ao ouvir o nome do seu cargo.

As respostas foram tabuladas segundo o padrão de características apresentadas (positivas ou negativas) e separadas conforme fossem mais diretamente ligadas ao cargo ou à pessoa do auditor. Tais categorizações foram estabelecidas de acordo com a percepção dos pesquisadores e as respostas, dispostas num quadro e submetidas à análise que permitiu formular as considerações acerca da identidade profissional dos servidores fiscais.

\section{Quadro 1 - Grelha de análise da $1^{\underline{a}}$ etapa da pesquisa}

\begin{tabular}{|c|c|c|}
\hline \multicolumn{3}{|c|}{ Auditor fiscal da receita federal } \\
\hline & Inerentes ao cargo & Inerentes à pessoa \\
\hline \multirow{12}{*}{ 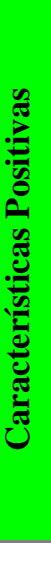 } & Autoridade & Competência \\
\hline & Estabilidade & Astúcia \\
\hline & Poder & Curioso \\
\hline & Remuneração & Dedicado \\
\hline & Respeito & Orgulhoso \\
\hline & Investigação & Formação \\
\hline & Responsabilidade & Integridade \\
\hline & & Inteligência \\
\hline & & Interesse \\
\hline & & Qualidade \\
\hline & & Estudo \\
\hline & Inerentes ao cargo & Inerentes à pessoa \\
\hline \multirow{10}{*}{ 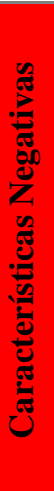 } & Chateação & Desconfiado \\
\hline & Aborrecimento & Chato \\
\hline & Complexidade & Corrupto \\
\hline & Falta de segurança & Bravo \\
\hline & Metas & Orgulhoso \\
\hline & Preocupação & Presunçoso \\
\hline & & Preguiçoso \\
\hline & & Falsidade \\
\hline & & Rígido \\
\hline & & FDP \\
\hline
\end{tabular}

Fonte: Dados da pesquisa

A forma como o indivíduo se vê - e como ele é visto pelos demais - é ponto fundamental no processo de formação da identidade, conforme estabelecido por Dubar (2003, 2005, 2006) e Machado (2003, 2005). Os processos de identificação dos auditores com a sua carreira e com a sua organização, bem como a forma como desempenham suas tarefas, fornecem elementos de análise para que se possa estudar essa categoria profissional. 
Apesar de se ver como um profissional competente e com boa formação intelectual, as respostas indicam que há características negativas marcantes que povoam a mente dos auditores em relação a si e aos outros integrantes da classe, como a preguiça, a presunção e a corrupção. Houve ainda uma razoável dúvida quanto a algumas palavras, como autoridade, associada ao cargo, dado que não há como saber se é uma efetiva característica ou uma necessidade.

Outra informação revelada nesse primeiro momento é a de que, apesar do forte orgulho por ser integrante da carreira - a maioria se vê como vencedor de uma disputa muito acirrada para ingresso na organização -, não há grande afinidade com as tarefas desempenhadas. Nesse sentido, foi observado no decorrer da pesquisa que as pessoas entrevistadas pouco falaram sobre suas experiências profissionais, mas demonstraram forte interesse pelo pertencimento à carreira, evidenciando certa contradição entre ser auditor e o desempenho das tarefas inerentes à função.

Esse ponto revela que, apesar dos esforços para mudar o modelo burocrático para o gerencial - visando alterar a filosofia do serviço público, deslocando o foco dos meios para os fins - ainda há fortes traços da lógica burocrática permeando as relações e o sentimento dos funcionários da organização. Certamente, observa-se um afastamento em relação à tradição patrimonialista, mas algo ainda muito distante do desejo da sociedade por serviços públicos de qualidade.

A perda da autoridade vem sendo debatida pelos auditores fiscais da Receita Federal do Brasil em suas proposições, o que pode contribuir para que sejam conhecidas, mais particularmente, as transformações por que passam a organização e seus profissionais. Muitos pensam que o exercício da atividade fiscal pode estimular nos cidadãos o sentimento de que a profissão seja privilegiada e que seus integrantes devem estar a serviço da sociedade, sem a necessidade de salvaguardas especiais destacadas do conjunto dos servidores públicos. Outros creem que a autoridade seja válida não para privilegiar os auditores fiscais individualmente, mas para assegurar, ao lado de outras garantias e prerrogativas, a sua independência no exercício das funções e a obtenção dos resultados esperados pela sociedade, sem que se sintam ameaçados ou enfraquecidos em sua atividade.

Em um segundo momento da pesquisa, as palavras colhidas na etapa inicial foram testadas segundo uma escala social. Nesta, de acordo com sua percepção acerca da afirmação realizada, o respondente podia assinalar sua resposta em sete posições possíveis entre o "totalmente verdadeiro" e o "totalmente falso", em algumas questões, e entre a "fraca correlação" e a "forte correlação", em outras. Essas perguntas foram enviadas por correio eletrônico a todos os auditores das duas unidades, retornando 35(trinta e cinco) respostas.

Nessa segunda fase da pesquisa, foi possível estabelecer uma correlação mais estreita entre algumas questões apresentadas, por terem sido constatadas respostas indicando forte tendência à confirmação ou à negação das proposições apresentadas. Somente essas serão apresentadas, pois aquelas respostas com maior tendência a uma posição "de centro" não revelam a adesão necessária para que se faça qualquer tipo de afirmação.

A primeira questão apresentada pedia que o respondente assinalasse a correlação entre o AFRFB e a responsabilidade. Como pode ser visto no gráfico 1- que representa o número de respondentes em cada uma das sete possíveis opções de respostas - o resultado revela não apenas que os auditores encaram sua atividade profissional com forte senso de responsabilidade, mas que também a consideram uma importante característica. 


\section{Gráfico 1}

\section{AFRFB x Responsabilidade}

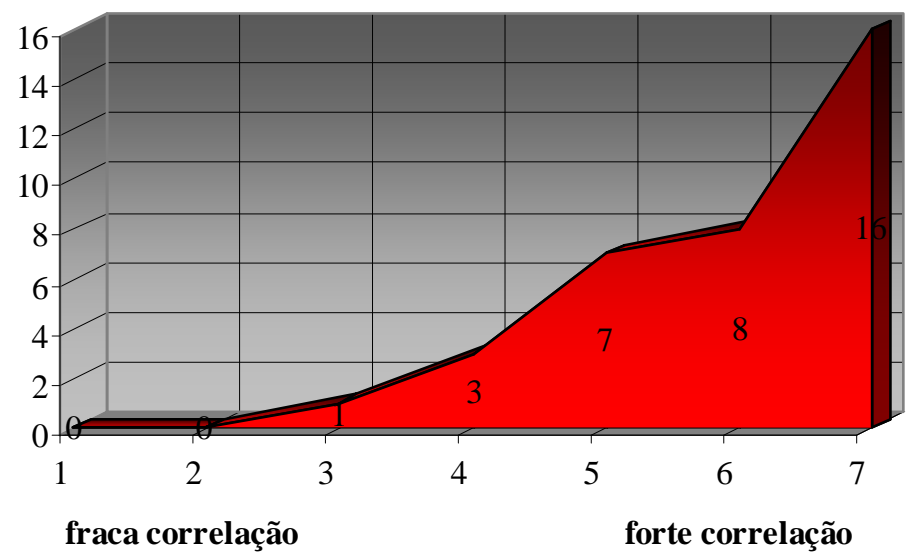

Fonte: Dados da pesquisa.

Outra questão apresentada aos servidores foi a seguinte: "Ser AFRFB é motivo de orgulho, pois seus integrantes são preparados, estudiosos, competentes e compõem uma das carreiras mais brilhantes do serviço público". As repostas apresentadas demonstram que, para a maioria, é motivo de orgulho ser auditor fiscal e que o modo como veem seus pares é muito positivo. O gráfico 2 é elaborado a partir das respostas a esse questionamento, as quais produziram uma forte concentração à direita, reservada àqueles que consideraram essa questão totalmente verdadeira.

\section{Gráfico 2}

\section{AFRFB x Orgulho}

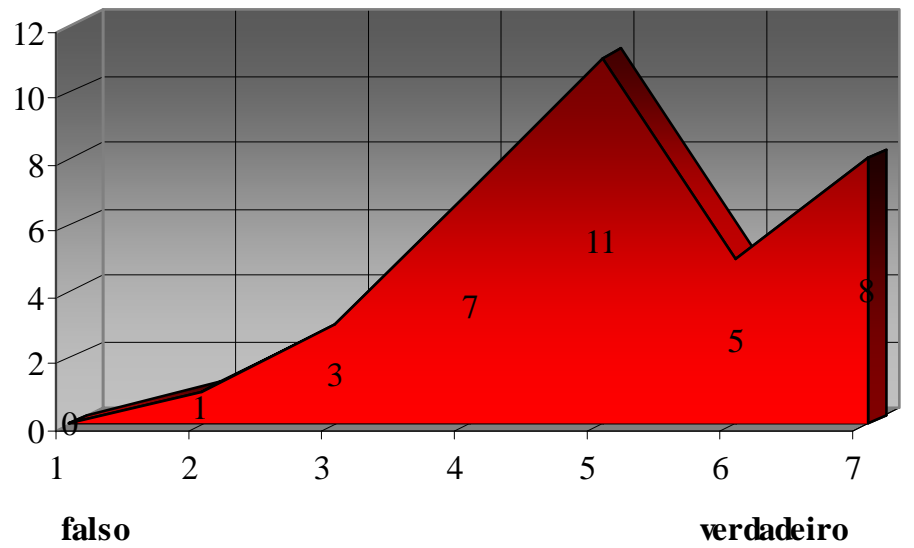

Fonte: Dados da pesquisa.

Em contrapartida, muitas respostas foram reveladoras do nível de identificação dos integrantes da carreira com a sua organização. A pergunta "A administração da organização dá pouca importância aos seus profissionais. O que dificulta o processo de identificação com a RFB, fazendo com seus profissionais se empenhem menos do que poderiam?" trouxe o seguinte resultado: a organização, por meio de seus administradores, não valoriza seus integrantes o quanto seria por eles desejável, conforme revelado pelo gráfico 3. 


\section{Gráfico 3}

\section{Comprometimento da Administração}

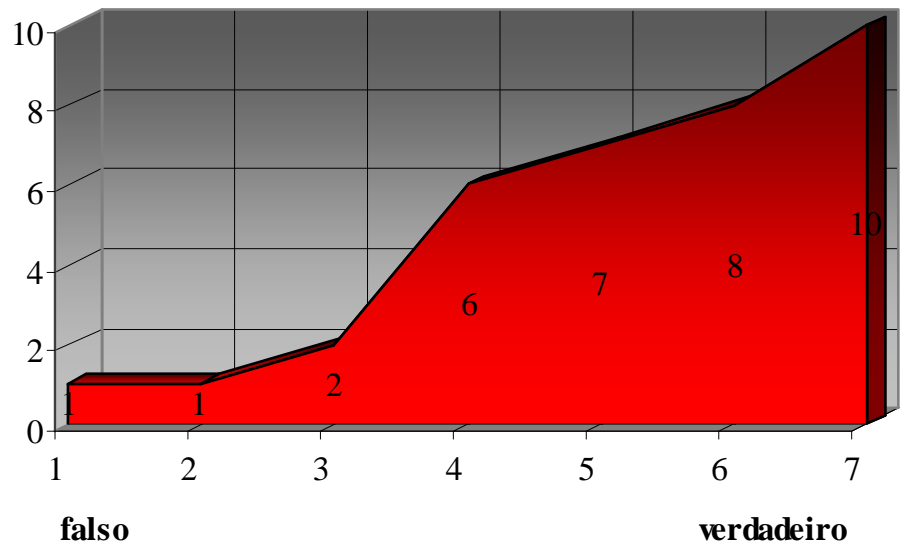

Fonte: Dados da pesquisa.

Ainda assim, o questionamento "Não tenho medo das mudanças na RFB, pois sou preparado e aberto a desafios" - cujas respostas estão tabuladas no gráfico 4 -, revelou que os auditores estão conscientes de sua responsabilidade diante do novo papel a ser desempenhado dentro do órgão e que há motivação suficiente para enfrentarem os desafios daí advindos.

\section{Gráfico 4}

\section{Abertura a desafios}

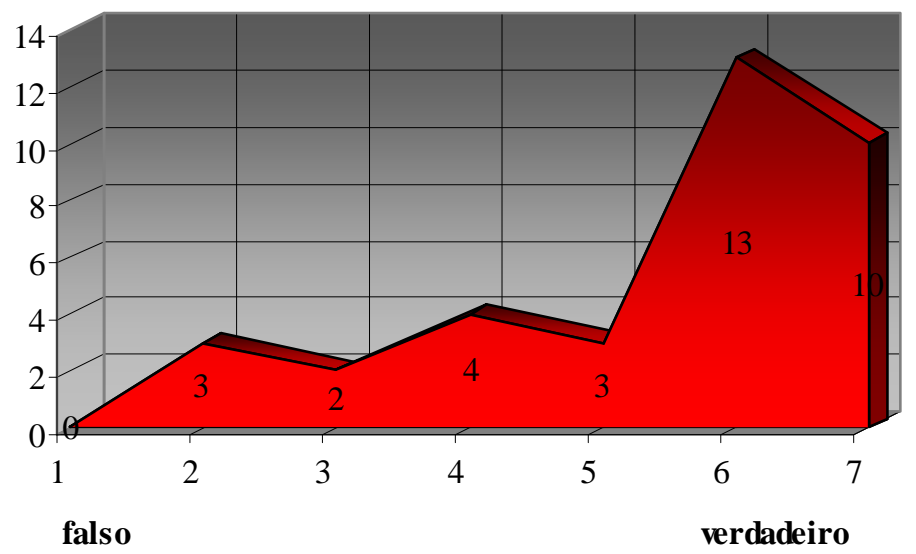

Fonte: Dados da pesquisa.

$\mathrm{Na}$ terceira fase da pesquisa, a realização de nove entrevistas permitiu aprofundar alguns aspectos das percepções e dos processos de identificação dos auditores fiscais. $\mathrm{O}$ tratamento das entrevistas possibilitou a elaboração do quadro 2, segundo dois eixos distintos de avaliação. O primeiro eixo, de características aglutinadoras, buscou palavras e frases que pudessem demonstrar um sentimento de pertencimento e de valorização da categoria profissional, seja por orgulho em ser parte de uma classe, seja pelo exercício de uma atividade relevante para a sociedade. 


\section{Quadro 2 - Análise temática das entrevistas}

\begin{tabular}{|c|c|c|}
\hline \multirow[b]{3}{*}{ Categorias } & \multirow{2}{*}{\multicolumn{2}{|c|}{ Características }} \\
\hline & & \\
\hline & Agregadoras & Desagregadoras \\
\hline \multirow{4}{*}{ Exercício de papéis } & $\begin{array}{l}\text { Aproveitamento de saberes e } \\
\text { experiências acumuladas na trajetória } \\
\text { escolar e profissional }\end{array}$ & $\begin{array}{l}\text { Pouca dedicação ao trabalho e } \\
\text { prioridade aos projetos pessoais fora da } \\
\text { organização }\end{array}$ \\
\hline & Satisfação com a remuneração & Perda de status social \\
\hline & \multirow{2}{*}{$\begin{array}{l}\text { Atuação polivalente que permite } \\
\text { conciliar a atividade com a formação } \\
\text { escolar }\end{array}$} & $\begin{array}{l}\text { Ser auditor: orgulho no passado e } \\
\text { vergonha no presente }\end{array}$ \\
\hline & & Perda de autonomia \\
\hline \multirow{2}{*}{ Reconhecimento } & \multirow{2}{*}{$\begin{array}{l}\text { Possibilidade de promoção na } \\
\text { organização }\end{array}$} & $\begin{array}{l}\text { Falta de reconhecimento das funções e } \\
\text { cargos exercidos }\end{array}$ \\
\hline & & $\begin{array}{l}\text { Perda da liberdade diante do aumento do } \\
\text { controle }\end{array}$ \\
\hline \multirow{4}{*}{ Simbolismos } & $\begin{array}{l}\text { Construção de uma imagem positiva do } \\
\text { servidor público }\end{array}$ & Insatisfação com a função de fiscal \\
\hline & Estabilidade e salário elevado & $\begin{array}{l}\text { Perda da visão romântica sobre a } \\
\text { importância social do auditor }\end{array}$ \\
\hline & \multirow{2}{*}{$\begin{array}{l}\text { Reconhecimento da produtividade do } \\
\text { sujeito }\end{array}$} & Desgosto e infelicidade com a profissão \\
\hline & & $\begin{array}{l}\text { Sentimento de desconforto perante o } \\
\text { exercício de fiscalizar }\end{array}$ \\
\hline \multirow{3}{*}{ Mudanças estruturais } & Perfil mais gerencial da Receita & Perda de poder de decisão \\
\hline & $\begin{array}{l}\text { A profissão se torna complexa e } \\
\text { especializada }\end{array}$ & Rotinização das funções \\
\hline & $\begin{array}{l}\text { Tendência à especialização em termos } \\
\text { de formação acadêmica }\end{array}$ & Perda de autoridade \\
\hline \multirow{2}{*}{ Valorização profissional } & \multirow{2}{*}{$\begin{array}{l}\text { A estabilidade, o salário e a ausência de } \\
\text { cobrança de desempenho criam } \\
\text { condições para o investimento } \\
\text { profissional. }\end{array}$} & Pouco estímulo à especialização \\
\hline & & Descaso do órgão com seus funcionários \\
\hline \multirow{4}{*}{ Perfis identitários } & $\begin{array}{l}\text { Percepção favorável da categoria em } \\
\text { termos intelectuais e morais }\end{array}$ & $\begin{array}{l}\text { Arrogância, limitação intelectual e falta } \\
\text { de cultura dos profissionais. }\end{array}$ \\
\hline & \multirow{3}{*}{$\begin{array}{l}\text { Polivalência, discernimento, audácia, } \\
\text { objetividade, bom senso e sentimento de } \\
\text { justiça. }\end{array}$} & $\begin{array}{l}\text { Falta de valorização da carreira afeta a } \\
\text { consciência da importância da profissão }\end{array}$ \\
\hline & & $\begin{array}{l}\text { Investimento na formação sem } \\
\text { compromisso com a Receita }\end{array}$ \\
\hline & & $\begin{array}{l}\text { Falta de capacidade de raciocínio lógico } \\
\text { e de meticulosidade exigidos na função }\end{array}$ \\
\hline
\end{tabular}

Fonte: Dados da pesquisa.

O segundo eixo, de características desagregadoras, identificou elementos nos discursos que mais afastam do que aglutinam os servidores em torno da organização, além de tornarem o discurso permeado por palavras de desagrado quanto à profissão e à forma de desempenho das atividades. A partir das falas dos entrevistados, é possível perceber o que mais motiva a opção pela carreira de AFRFB: o binômio estabilidade/salário. Outros fatores são a percepção de que terão maior tranquilidade na execução de suas tarefas e de que irão atingir maior 
status social, tendo sido apontados ainda falta de identificação com a formação acadêmica anterior e até formação direcionada para o concurso público.

\section{Em forma de conclusão}

A pesquisa revela que os auditores são profissionais com senso de responsabilidade, conscientes das mudanças profissionais e que, apesar de não ser possível mensurar sua concordância ou não com tais mudanças, há disposição para enfrentá-las. Isso ocorre apesar da percepção das perdas nas suas atribuições e na sua autoridade, bem como da falta de comprometimento da organização com um projeto de implementação gradativa das alterações que contemple os servidores com as necessárias medidas de apoio.

Os profissionais ouvidos veem a organização menos como parceira de sua atividade e mais como um ente que quer reduzir a importância de seu trabalho, retirando suas atribuições, estabelecendo metas inatingíveis e enfraquecendo sua autoridade. Contudo, eles se consideram capazes e motivados, e buscam construir seu perfil identitário com o exercício de uma atividade complexa e cheia de desafios.

A identidade profissional dos Auditores-Fiscais da Receita Federal do Brasil, assim como a identidade profissional de outras categorias profissionais, está em constante processo de construção, sendo impossível estabelecer uma característica única que possa ser utilizada para designá-la. No entanto, ao longo do trabalho, foi possível conhecer pontos em comum entre seus integrantes, revelados em suas falas, que revelam preocupações e anseios desses trabalhadores com sua organização, com a sociedade em que vivem e com o futuro de cada um deles.

Esse quadro leva a crer que não há uma carreira única, nem uma única categoria, mas diversas categorias, com suas especificidades e rotinas, tendo em comum apenas a denominação jurídica e o nome do cargo. Entretanto, se por um lado tamanha diversidade enriquece a classe, por outro, pode enfraquecer o sentimento de pertencimento a uma única categoria profissional. 


\section{Referências}

BARDIN, Laurence. Análise de conteúdo. Lisboa: Ed. 70, 2006.

BRASIL. Ministério do Planejamento. Plano Diretor da Reforma do Estado. Brasília, DF, 1995. Disponível em: <www.mpog.gov.br>. Acesso em: 20 maio 2007.

BRESSER-PEREIRA, Luiz Carlos. Da administração pública burocrática à gerencial. Revista do Serviço Público, v.47, n.1, p.7-29, 1996.

CASTOR, B; JOSÉ, H. Reforma e contra-reforma: a perversa dinâmica da administração pública brasileira. Revista de Administração Pública, no 32, pp. 97-111, nov-dez, 1998.

CROZIER, Michel. O fenômeno burocrático. Brasília, DF: Ed. UnB, 1981.

DUBAR, Claude. Trajetórias sociais e formas identitárias: alguns esclarecimentos conceituais e metodológicos. Educação e Sociedade, Campinas, v.19, n.62, 1998. Disponível em: <http://www.scielo.br/scielo.php?script=sci_arttext\&pid=S010173301998000100002\&lng=pt\&nrm=iso>. Acesso em: 30 jun. 2007. Pré-publicação.

Formação, trabalho e identidades profissionais. In: CANÁRIO, Rui (Org.). Formação e situações de trabalho. Porto: Porto Editora, 2003.

A socialização: construção das identidades sociais e profissionais. São Paulo: Martins Fontes, 2005.

A crise das identidades - a interpretação de uma mutação. Porto: Edições Afrontamento, 2006.

MACHADO, Hilka Vier. A identidade e o contexto organizacional: perspectivas de análise. Revista de Administração Contemporânea - RAC, edição especial, p. 51-73, 2003. n.1, 2005.

Identidade organizacional: um estudo de caso no contexto da cultura brasileira. RAE eletrônica, São Paulo, v.4,

PAULA, Ana Paula Paes. Por uma nova gestão pública. Rio de Janeiro: Editora FGV, 2007.

PEDRO, Wilson J. Alves. Reflexões sobre a categoria identidade através de uma perspectiva interdisciplinar. Revista Uniara, n. 19, p. 67-74, 2006.

STRAUSS, Anselm L. Espelhos e máscaras: a busca de identidade. São Paulo: Edusp, 1999.

WEBER, Max. Ensaios de sociologia. Rio de Janeiro: Ed. LTC, 2002.

Economia e sociedade. Brasília, DF: Ed. UnB, v.1, 2004. 